\title{
Predictive value of 3-month lumbar discectomy outcomes in the NeuroPoint-SD Registry
}

\author{
Robert G. Whitmore, MD, ${ }^{1,2}$ Jill N. Curran, MS, ${ }^{1,2}$ Zarina S. Ali, MD, ${ }^{3}$ Praveen V. Mummaneni, MD, ${ }^{4}$ \\ Christopher I. Shaffrey, MD, ${ }^{5}$ Robert F. Heary, MD, ${ }^{6}$ Michael G. Kaiser, MD, ${ }^{7}$ Anthony L. Asher, MD, ${ }^{8}$ \\ Neil R. Malhotra, MD, ${ }^{3}$ Joseph S. Cheng, MD, ${ }^{9}$ John Hurlbert, MD, ${ }^{10}$ Justin S. Smith, MD, PhD, ${ }^{5}$ \\ Subu N. Magge, MD, ${ }^{1}$ Michael P. Steinmetz, MD, ${ }^{11}$ Daniel K. Resnick, MD, ${ }^{12}$ and \\ Zoher Ghogawala, MD ${ }^{1,2}$
}

${ }^{1}$ Alan and Jacqueline Stuart Spine Research Center, Department of Neurosurgery, Lahey Hospital and Medical Center, Burlington, Massachusetts; ${ }^{2}$ Wallace Trials Center, Greenwich Hospital, Greenwich, Connecticut; ${ }^{3}$ Department of Neurosurgery, University of Pennsylvania, Philadelphia, Pennsylvania; ${ }^{4}$ Department of Neurological Surgery, University of California, San Francisco, California; ${ }^{5}$ Department of Neurosurgery, University of Virginia, Charlottesville, Virginia; ${ }^{6}$ Neurological Surgery, Rutgers New Jersey Medical School, Newark, New Jersey; ${ }^{7}$ Department of Neurosurgery, Columbia University, New York, New York; ${ }^{8}$ Carolina Neurosurgery \& Spine, Charlotte, North Carolina; ${ }^{2}$ Department of Neurological Surgery, Vanderbilt University Medical Center, Nashville, Tennessee; ${ }^{10}$ Department of Clinical Neurosciences, University of Calgary Spine Program, Calgary, Alberta, Canada; ${ }^{11}$ MetroHealth Medical Center, Cleveland, Ohio; ${ }^{12}$ Department of Neurological Surgery, University of Wisconsin School of Medicine and Public Health, Madison, Wisconsin

OBJECT The authors have established a multicenter registry to assess the efficacy and costs of common lumbar spinal procedures using prospectively collected outcomes. Collection of these data requires an extensive commitment of resources from each site. The aim of this study was to determine whether outcomes data from shorter-interval follow-up could be used to accurately estimate long-term outcome following lumbar discectomy.

METHODS An observational prospective cohort study was completed at 13 academic and community sites. Patients undergoing single-level lumbar discectomy for treatment of disc herniation were included. SF-36 and Oswestry Disability Index (ODI) data were obtained preoperatively and at 1, 3, 6, and 12 months postoperatively. Quality-adjusted life year (QALY) data were calculated using SF-6D utility scores. Correlations among outcomes at each follow-up time point were tested using the Spearman rank correlation test.

RESULTS One hundred forty-eight patients were enrolled over 1 year. Their mean age was 46 years ( $49 \%$ female). Eleven patients $(7.4 \%)$ required a reoperation by 1 year postoperatively. The overall 1 -year follow-up rate was $80.4 \%$. Lumbar discectomy was associated with significant improvements in ODI and SF-36 scores $(p<0.0001)$ and with a gain of 0.246 QALYS over the 1-year study period. The greatest gain occurred between baseline and 3-month follow-up and was significantly greater than improvements obtained between 3 and 6 months or 6 months and 1 year $(p<0.001)$. Correlations between 3-month, 6-month, and 1-year outcomes were similar, suggesting that 3-month data may be used to accurately estimate 1 -year outcomes for patients who do not require a reoperation. Patients who underwent reoperation had worse outcomes scores and nonsignificant correlations at all time points.

CONCLUSIONS This national spine registry demonstrated successful collection of high-quality outcomes data for spi-

\footnotetext{
ABBREVIATIONS IRB = institutional review board; $M C I D=$ minimum clinically important difference; $O D I=$ Oswestry Disability Index; $Q A L Y=$ quality-adjusted life year; QOL = quality of life; SF-36 = 36-Item Short-Form Health Survey; SPORT = Spine Patient Outcomes Research Trial; VAS = visual analog scale.

SUBMITTED August 30, 2014. ACCEPTED January 15, 2015

INCLUDE WHEN CITING Published online July 3, 2015; DOI: 10.3171/2015.1.SPINE14890.

DISCLOSURE Funding for this work was provided by the AANS/CNS Joint Section on Disorders of the Spine and Peripheral Nerves and the Jean and David Wallace Foundation (GH382). Dr. Mummaneni reports direct stock ownership in Spinicity and receipt of royalties and honoraria from DePuy, honoraria from Globus, and royalties from the following publishers: Thieme, Taylor and Francis, and Springer. Dr. Shaffrey reports a consultant relationship with Biomet, Globus, Medtronic, NuVasive, and Stryker; direct stock ownership in NuVasive; and receiving royalties from and/or holding patents with Biomet, Medtronic, and NuVasive. Dr. Heary reports receiving royalties from DePuy Spine and Zimmer Spine unrelated to this study and the content of this article. Dr. Smith reports a consultant relationship with Biomet, NuVasive, Cerepedics, Globus, DePuy, and Medtronic; receiving royalties from Biomet; receiving support for non-study-related clinical or research effort from DePuy; and receiving fellowship support from NREF and AOSpine. Dr. Steinmetz reports a consultant relationship with Biomet, DePuy, Stryker, Intellirod, and Medtronic.
} 
nal procedures in actual practice. Three-month outcome data may be used to accurately estimate outcome at future time points and may lower costs associated with registry data collection. This registry effort provides a practical foundation for the acquisition of outcome data following lumbar discectomy.

Clinical trial registration no.: NCT01220921 (clinicaltrials.gov)

http://thejns.org/doi/abs/10.3171/2015.1.SPINE14890

KEY WORDS discectomy; outcome; correlation; QALY; lumbar

$\mathrm{L}$ UMBAR discectomy is one of the most commonly performed surgical procedures in the United States, accounting for almost 200,000 cases per year. ${ }^{26}$ Generally, surgery for herniated lumbar discs is performed after failure of a trial of nonoperative management. ${ }^{6}$ The goal of surgical treatment is to achieve decompression of neural elements by removing disc material in order to improve the patient's symptoms and quality of life (QOL). Multiple studies have demonstrated that surgical intervention for patients with symptomatic lumbar disc herniation results in early improvement of symptoms. . $, 8,20,22,28^{2}$

Patient-reported outcomes data on the surgical treatment of lumbar disorders are of significant interest to numerous parties, including patients, clinicians, payers, and policy-makers. In 2010, the Neurosurgery Patient Outcomes IN Treating Spinal Disorders (NeuroPoint-SD) project was designed to establish a multicenter cooperative group to prospectively collect patient outcomes data on the surgical treatment of lumbar spinal disorders, including lumbar discectomy. Based on data from this registry, it was demonstrated that lumbar discectomy and lumbar spinal fusion for degenerative lumbar spondylolisthesis were effective in improving QOL using validated general and disease-specific outcome instruments, the 36-item ShortForm Health Survey (SF-36), Oswestry Disability Index (ODI), and a visual analog scale (VAS). ${ }^{9}$

Collection of patient-reported outcomes data in NeuroPoint-SD required dedicated research personnel at multiple institutions, data management and analysis experts, and was associated with significant costs. One of the major drivers of cost, as well as the challenges to overall validity for registries, is the ability to obtain 1-year follow-up on all patients. Currently, there are no standard protocols dictating the duration of follow-up required for collecting patient-reported outcomes to determine clinical effectiveness for lumbar discectomy. The purpose of this analysis is to correlate the outcome scores following lumbar discectomy at standard follow-up time points to determine if data collection at 3 months or 6 months might serve as a valid surrogate for long-term outcomes. Ultimately, the success of patient-reported outcome registries will depend on developing practical guidelines for the optimal data acquisition time period to determine clinical effectiveness for lumbar spine procedures.

\section{Methods}

This trial was registered with the Clinical Trials.gov database (www.clinicaltrials.gov), and its registration number is NCT01220921.

\section{Study Design}

A prospective, observational cohort registry study enrolled patients from 13 sites over a 1-year period and collected data from unselected patients undergoing lumbar discectomy. Outcomes were measured and observed over a 1-year period postoperatively.

\section{Data Coordination}

Institutional review board (IRB) approval of the clinical protocol was obtained and research contracts were executed for this prospective registry at 13 academic and community sites nationwide in September 2010. Patient data were managed at the central coordinating center (Wallace Clinical Trials Center in Greenwich, Connecticut). All patient data were de-identified before transfer from each treating institution to protect patient confidentiality, in compliance with the Health Insurance Portability and Accountability Act (HIPAA). All patient data were entered into a secure, HIPAA-compliant, internet-based data management platform, the NeuroPoint Alliance (NPA), which was developed by Outcome Sciences (Cambridge, Massachusetts) in conjunction with the American Association of Neurological Surgeons (AANS) (Rolling Meadows, Illinois). Enrollment occurred over a 1-year period (September 2010-September 2011) and data collection was completed in September 2012.

\section{Data Sources/Measurement}

All questionnaires were administered in the outpatient office setting. In certain circumstances, 6-month or 1-year follow-up was not performed as routine clinical care. In these situations, the patients were mailed the questionnaires to complete and return to the study site coordinator. Patients completing the questionnaires at home were instructed to call the study site coordinators with any questions. In addition, site coordinators reviewed the questionnaires for completeness. Patients were contacted via phone to assess work status, to document any complications during the study period, and to address and complete any missing data from the questionnaires. Each patient who did not return the follow-up questionnaires was contacted 3 times via mail and/or phone calls to optimize patient compliance.

Expenses for the study were estimated from the budgeted IRB expenses and patient incentive reimbursements. Administrative costs were based on $20 \%$ full-time equivalence for study coordinators at each site. These were used to compile Table 1. 
TABLE 1. Expenses for the NeuroPoint-SD study at each site for 1 year's follow-up and predicted expenses for 3 months' follow-up (13 sites)

\begin{tabular}{lrc}
\hline \multirow{2}{*}{ Expense } & \multicolumn{2}{c}{ Follow-Up (\$) } \\
\cline { 2 - 3 } & 1 Year & 3 Months \\
\hline Site IRB fees & 2500 & 2500 \\
\hline Site administrative costs & 14,000 & 3500 \\
\hline Patient incentive reimbursement & 2000 & 1000 \\
\hline Total & 18,500 & 7000 \\
\hline
\end{tabular}

\section{Study Population}

Patients aged 18-80 years with symptomatic lumbar disc herniation refractory to noninvasive therapies for at least 6 weeks were eligible. Patients were excluded for any of the following reasons: 1) history of previous lumbar spinal surgery at the level of disc herniation; 2) significant motor weakness on manual muscle testing of $3 / 5$ or less (i.e., foot drop) or cauda equina syndrome; 3) cancer, infection, or fracture involving any portion of the spine; or 4) pregnancy. Each site was permitted to enroll up to 25 unselected patients within the 1-year study period.

Patients were recruited from 13 sites without regard to sex, race, age, language preference, or socioeconomic status. There was no specific advertising to recruit patients, although the clinical registry was listed with www. clinicaltrials.gov and on most of the participating institution's clinical research web pages. All potentially eligible patients were screened by a study coordinator for potential enrollment. The screening log for NeuroPoint-SD has been published and demonstrates that $80 \%$ of eligible patients were enrolled. ${ }^{9}$ Eligible patients were enrolled over an average of 6 months at each site until the national accrual goal was reached. All patients who were eligible, and who agreed to participate, were asked to sign an IRB-approved consent form for participation in the study. The patient's treatment was not affected in any way by choosing not to participate in the study.

\section{Outcomes Assessment}

Patients completed 1 disease-specific outcome measure, the Oswestry Disability Index (ODI $)^{7}$ and 1 general health-related QOL measure, the norm-based SF-36, ${ }^{12}$ preoperatively, and at 1,3,6, and 12 months postoperatively.

\section{Surgical Treatment}

In all cases, surgical treatment was undertaken at the discretion of the surgeon and the patient. Lumbar discectomy was performed as described. ${ }^{25}$

\section{Study Sample Size Estimates}

Based on the published data for the lumbar discectomy patients from the SPORT trials ${ }^{27}$ we assumed a preoperative value of 30 for SF-36 physical function, with a standard deviation between 23 and 25 , with treatment effect from 40-45 points. For a 2 -sided, 5\% significance level, we calculated that a sample size of 10 patients per site would be necessary to demonstrate the effectiveness of lumbar discectomy at $80 \%$ power, leading to the total sample size estimate for the lumbar discectomy cohort of 100 patients. The sample size was inflated to 125 patients to accommodate attrition during follow-up.

\section{Statistical Analysis}

Mean values and standard deviations were calculated for outcomes assessments, and improvement in outcome was evaluated using paired t-tests and repeated-measures ANOVA. To calculate QALYs, we first converted SF-36 data to SF-6D using ordinal and standard gamble health state valuation models. ${ }^{3-5,18}$ QALYs were determined by the change in utility between baseline and follow-up, multiplied by the duration of time in years at that follow-up point (i.e., 0.5 for 6 months or 1 for 1 year). ${ }^{10,23}$ One-year predicted QALYs gained (Table 2) were calculated by using the QALYs gained at each time point (i.e., 3 months) and multiplying by the appropriate factor to equal 1 year (i.e., 4 for 3 months and 2 for 6 months). Correlations among outcomes at each follow-up time point were tested using the Spearman rank correlation test. The Spearman rho, a measure of statistical dependence between 2 nonparametric variables, is depicted and represents the degree of correlation. The closer Spearman rho is to 1 or -1 , the stronger the relationship is considered. Outcomes tested included the SF-36, ODI, and QALYs gained. A p value less than 0.05 was considered statistically significant. Analyses were performed using Stata (version 12.1, StataCorp).

\section{Results}

\section{Baseline Demographics and Compliance}

Patients who underwent lumbar discectomy $(\mathrm{n}=148)$ were enrolled from 13 sites and were included in the current analysis. The patients' mean age was 46 years and the median body mass index was 27.3 (49\% female, $2 \%$ with diabetes, and $21 \%$ smokers).

Baseline evaluations were completed in $100 \%$ of patients. Outcomes assessment compliance (follow-up) among patients who underwent lumbar discectomy was $94.6 \%$, $85.8 \%, 83.1 \%$, and $80.4 \%$ at $1,3,6$, and 12 months, respectively.

\section{Outcomes Assessment}

At 1-month follow-up, lumbar discectomy was associated with an average improvement of 22.7 and 20.4 points in SF-36 and ODI scores, respectively $(\mathrm{p}<0.001)$. This significant improvement in both SF-36 and ODI persisted through the 1-year follow-up (Fig. 1). The average number of QALYs gained at 1 year following lumbar discectomy was 0.246, and the average improvement in SF-36 and ODI scores was 42.0 and 30.5, respectively. Most of the improvement in outcomes for SF-36 and ODI occurred during the first 3 months after surgery and additional improvements beyond this time point were not significant (see Table 3).

Patients who underwent a reoperation within the 1-year postoperative period did not experience statistically significant improvements in SF-36 and ODI scores until 6 
TABLE 2. Actual and predicted QALYs gained at follow-up

\begin{tabular}{clccc}
\hline \multicolumn{1}{c}{ Patient Cohort } & 1 Month & 3 Months & 6 Months & 1 Year \\
\hline Entire cohort & & & & \\
\hline Actual QALYs gained & 0.01 & 0.05 & 0.11 & 0.25 \\
\hline Predicted 1-yr QALYs gained & 0.12 & 0.20 & 0.22 & 0.25 \\
\hline Patients who underwent reoperation $(n=11)$ & & & & 0.21 \\
\hline Actual QALYs gained & 0.0003 & 0.03 & 0.10 & 0.21 \\
\hline Predicted 1-yr QALYs gained & 0.004 & 0.12 & 0.20 & \\
\hline
\end{tabular}

months following the initial discectomy. In 9 of the 11 cases in which reoperation was performed, patients underwent reoperation by 6 months after the initial procedure. At 1 and 3 months' follow-up the average improvement in SF-36 score among patients who required reoperation was 8.2 and 15.0, respectively, and the corresponding improvements in ODI score were 5.5 and 10.2. At 1 year after surgery, improvements in SF-36 and ODI were 25.0 and 22.9, respectively ( $p=0.03$ and $p<0.01$, respectively), and the average number of QALYs gained was 0.209.

\section{Correlations Between Follow-Up Intervals}

Correlations among the outcome scores at each followup time point are summarized in Table 4. All the correlations are statistically significant, but they vary from moderate to very strong. The Spearman rho value for correlations between 1-month outcomes and the other follow-up time points ( 3 months, 6 months, and 1 year) are weaker than the values for later follow-ups. The correlations between 3-month and 1-year outcomes and between 6-month and 1-year outcomes are strong. This is depicted in Fig. 2 as a wider density in the scatterplot for 1 month versus 1 year and a tighter density in the graphs for 3 and 6 months. As can be seen in Table 2, analysis of data for the entire patient group showed that the predicted QALYs gained at 3 months and 6 months are similar to the actual QALYs gained at 1 year, but the predicted QALYs gained at 1 month were not.

To determine the predictive value of early (1-month, 3-month, and 6-month) patient-reported outcomes on the 1 -year outcomes in those patients who ultimately under-

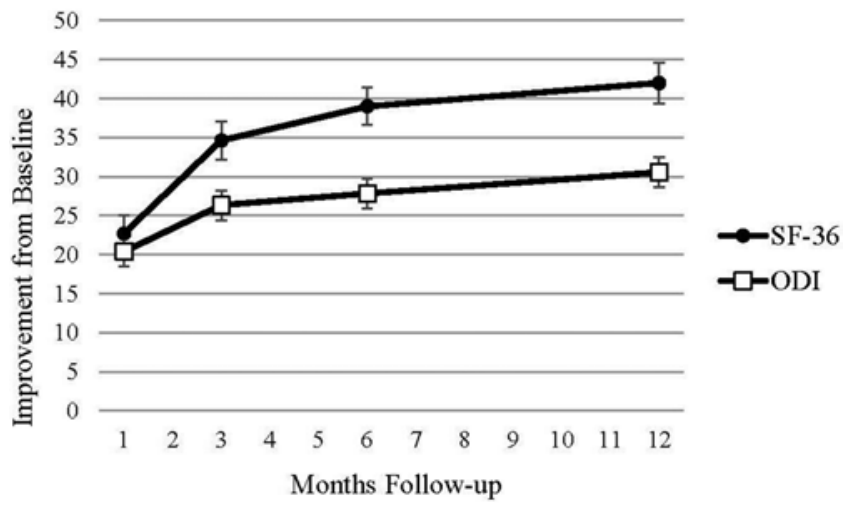

FIG. 1. Improvement in SF-36 and ODI scores from baseline to followup. Improvement from baseline was statistically significant at all time points from 1 month to 1 year $(p<0.001)$. went a reoperation within 1 year, an analysis was performed on only those patients who required a reoperation $(n=11)$. As summarized in the second half of Table 2, only the QALYs gained for 6 months predicted the actual QALY gained at 1 year. Three-month data were not predictive. In the corresponding analysis shown in the second half of Table 4, none of the Spearman correlations are statistically significant, but the 6-month outcomes may weakly predict 1-year outcomes.

\section{Discussion}

NeuroPoint-SD represents the first multicenter prospective registry to demonstrate clinical effectiveness for lumbar discectomy at 1 year. In this analysis, we have demonstrated that the outcomes following lumbar discectomy at 3 months may be used to accurately estimate the 1-year outcomes for patients who do not require reoperation. These outcomes include SF-36, ODI, and the QALYs gained. Most of the improvement in outcome following lumbar discectomy occurs within the first 3 months following the operation. For patients who developed reherniations and ultimately underwent reoperations, 6-month outcomes may predict long-term outcomes, but the correlation is weak. This is the first report to present guidelines for the duration of collection of outcomes following lumbar discectomy.

The NeuroPoint-SD registry has created the infrastructure to prospectively measure outcomes and costs of common spinal procedures. In addition to NeuroPoint-SD, there are several national spinal registry efforts currently

TABLE 3. Improvement in outcomes without inclusion of reoperation patients

\begin{tabular}{|c|c|c|c|}
\hline \multirow[b]{2}{*}{ Outcome Measure } & \multicolumn{3}{|c|}{ Improvement in Score } \\
\hline & 0-3 Months & 3-6 Months & 6 Months-1 Year \\
\hline $\begin{array}{l}\text { SF-36 score (mean } \\
\quad \pm \text { SD) }\end{array}$ & $36.5 \pm 26.5$ & $2.0 \pm 16.0$ & $3.3 \pm 13.7$ \\
\hline$p$ value & & $<0.001^{*}$ & $0.55 \dagger$ \\
\hline $\begin{array}{l}\text { ODI score (mean } \\
\quad \pm \text { SD) }\end{array}$ & $27.9 \pm 21.0$ & $1.5 \pm 10.5$ & $2.0 \pm 9.8$ \\
\hline$p$ value & & $<0.001^{*}$ & $0.80 \dagger$ \\
\hline
\end{tabular}

* For comparison of the gain in outcome between 0-3 months and 3-6 months, demonstrating that the majority of improvement after lumbar discectomy occurs in the first 3 months.

† For comparison of gain in outcome between 3-6 months and 6-12 months, demonstrating no statistically significant difference. 
TABLE 4. Spearman rank-order correlations among outcomes at each follow-up point

\begin{tabular}{|c|c|c|c|c|}
\hline Outcome Measure & 1 Month & 3 Months & 6 Months & 1 Year \\
\hline \multicolumn{5}{|l|}{ For all patients* } \\
\hline \multicolumn{5}{|l|}{ SF-36 } \\
\hline 1 year & 0.6260 & 0.8104 & 0.8509 & 1 \\
\hline \multicolumn{5}{|l|}{ ODI } \\
\hline 1 year & 0.7144 & 0.8219 & 0.8717 & 1 \\
\hline \multicolumn{5}{|l|}{ QALYs gained } \\
\hline 1 year & 0.4988 & 0.7510 & 0.7780 & 1 \\
\hline \multicolumn{5}{|c|}{ For patients who underwent reoperationt } \\
\hline \multicolumn{5}{|c|}{ SF-36 } \\
\hline 1 year & 0.460 & 0.246 & 0.629 & 1 \\
\hline \multicolumn{5}{|l|}{ ODI } \\
\hline 1 year & 0.055 & 0.176 & 0.533 & 1 \\
\hline \multicolumn{5}{|l|}{ QALYs gained } \\
\hline 1 year & 0.139 & 0.309 & 0.583 & 1 \\
\hline
\end{tabular}

underway to collect high-quality prospective outcome data. These include the National Neurosurgery Quality and Outcomes Database ( $\left.\mathrm{N}^{2} \mathrm{QOD}\right)$, which has modules in cervical spine and lumbar spine deformity, as well as the North American Spine Society (NASS) Spine Registry (https://www.spine.org/Pages/ResearchClinicalCare/ Research/SpineRegistry.aspx). ${ }^{1}$ All registry efforts have focused on creating a low-cost and accessible platform for prospective data collection. The average follow-up rate in NeuroPoint-SD was $86 \%$ at 3 months and $80 \%$ at 1 year. Obtaining such high rates of follow-up in NeuroPoint-SD required significant resource commitment from all participating institutions. For 1 year of data collection, we previously estimated a cost of more than $\$ 1800$ per patient, ${ }^{9}$ and most NeuroPoint-SD sites incurred more than $\$ 18,000$ in actual costs to collect data for 1 year (Table 1). By collecting data for 3 months rather than 1 year, the costs per site would be reduced by nearly two-thirds ( $\$ 7000$ vs $\$ 18,500)$. Based upon this analysis, many smaller practices with limited funding or infrastructure could potentially be able to obtain meaningful long-term results by extrapolating from the 3-month data.

We have previously shown that the results of NeuroPoint-SD for lumbar discectomy are similar to those reported by a well-designed trial such as SPORT (Spine Patient Outcomes Research Trial).9,27 SPORT recently reported 8-year results for surgical versus nonoperative treatment for lumbar disc herniation. ${ }^{15}$ Using the as-treated analysis, the authors reported little to no degradation of outcomes to 8 years' follow-up after lumbar discectomy. The maintenance of gain in outcomes following lumbar discectomy, as demonstrated by this recent SPORT publication, are important for the conclusions of our analysis and have broader implications for spinal surgery registry design. These preliminary data suggest that 3-month outcome scores following lumbar discectomy may not change significantly for the duration of a patient's lifetime. For each spinal diagnosis and surgical procedure, there may exist a time point after which there is little variation in outcome scores. Accurately determining these time points would help to establish guidelines for data collection for prospective registries.

Although a small number of patients in this study underwent reoperation, the outcome scores for these patients were consistently worse, across all time points, than those for patients who did not require reoperation (Table 5). The minimum clinically important difference (MCID) for SF-36 subscales has been reported as 10 points, and for ODI it has been reported as $8-12$ points. ${ }^{11,16,21}$ For the total lumbar discectomy cohort in NeuroPoint-SD, the MCID for average improvement was reached 1 month following surgery. For patients who required a reoperation, their 3 -month outcome scores were significantly lower. The lower outcome scores of patients who underwent reoperation may represent an important "red flag" for providers. Additional workup, including imaging studies, may be indicated for patients with less than optimal outcome scores at 3 months following lumbar discectomy. Spinal registries may be helpful not only in validating the positive gains from surgery, but also in detecting those patients who are not doing well and might benefit from additional intervention. However, accurate lumbar disc reherniation rates would not be captured by registries that end data collection at 3 months. State inpatient claims databases and registries dedicated to capturing readmission rates would be essential to fully assess the rate of reoperation following lumbar discectomy. ${ }^{17}$

Spinal registries are also useful for cost-utility analyses. We recently published a study of the NeuroPoint data demonstrating that the 1-year cost/QALY ratio for lumbar discectomy $(\$ 66,578)$ is lower than the accepted societal willingness-to-pay threshold of $\$ 100,000 .^{13,14,19}$ Since 1-year QALYs gained following lumbar discectomy are greater than those observed at 3 months, it would not be accurate to use 3-month registry data for calculating cost-effectiveness. Multiple studies have demonstrated 

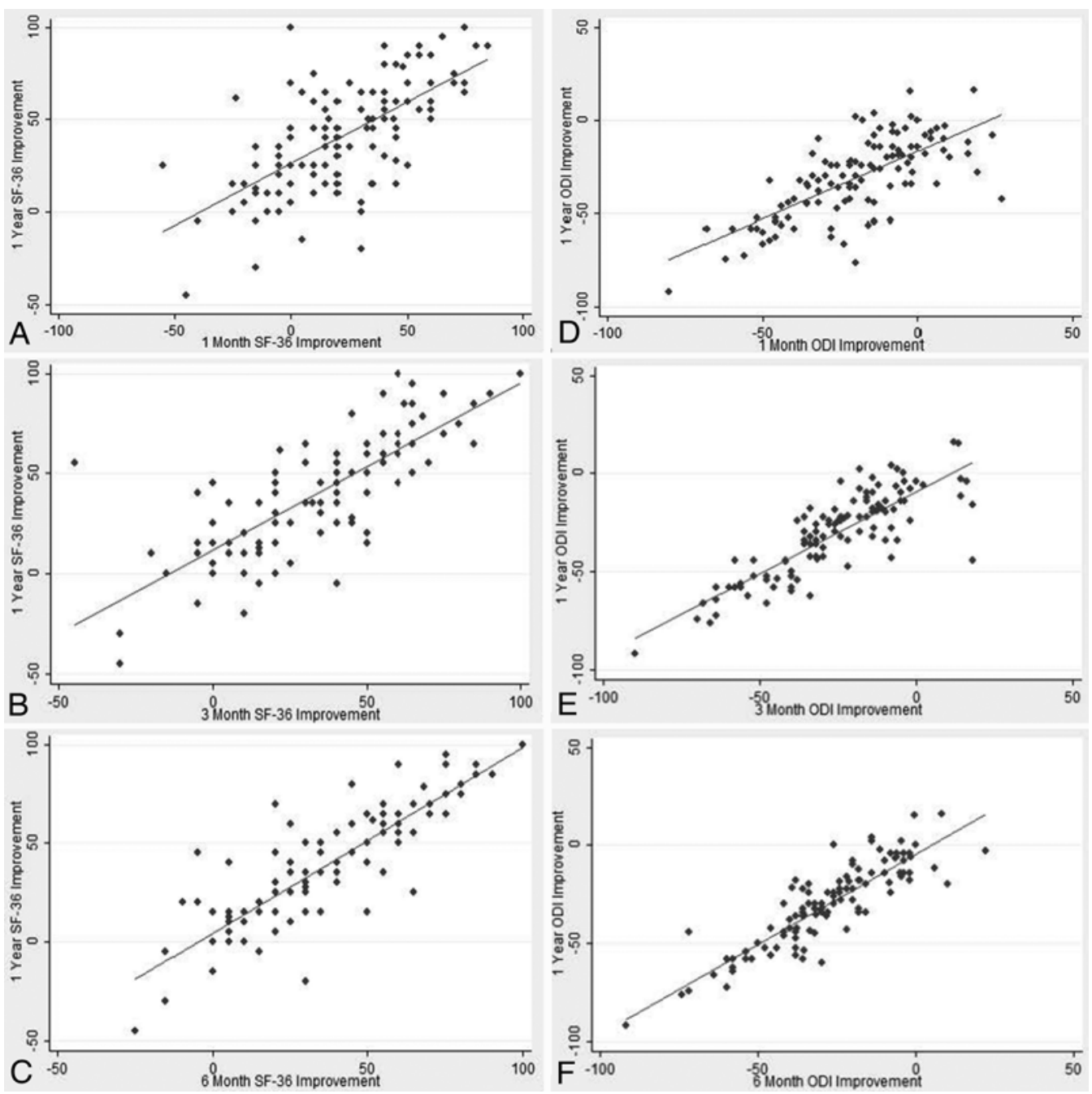

FIG. 2. Scatterplots showing improvement in SF-36 (A-C) and ODI (D-F) for 1 month versus 1 year $(A$ and $D), 3$ months versus 1 year (B and $E)$, and 6 months versus 1 year ( $C$ and $F)$.

TABLE 5. Comparison of outcome scores between patients with and without reoperation

\begin{tabular}{|c|c|c|c|c|c|}
\hline Outcome Measure & $\begin{array}{l}\text { Pts w/o reoperation } \\
\qquad(n=137) \dagger\end{array}$ & $\begin{array}{l}\text { Pts w/ reoperation } \\
\qquad(\mathrm{n}=11) \dagger\end{array}$ & p Value* & $\begin{array}{c}\% \text { of Pts w/o Reoperation } \\
\text { Who Achieved MCID }\end{array}$ & $\begin{array}{c}\% \text { of Pts w/ Reoperation } \\
\text { Who Achieved MCID }\end{array}$ \\
\hline \multicolumn{6}{|l|}{ SF-36 } \\
\hline Preop & $38.4(23.7)$ & $35.5(24.8)$ & & & \\
\hline 1 month & $63.1(25.1)$ & $43.6(26.2)$ & 0.08 & 73 & 55 \\
\hline 3 months & $76.3(23.1)$ & $50.5(24.9)$ & 0.01 & 85 & 45 \\
\hline 6 months & $78.8(23.4)$ & $68.0(22.4)$ & 0.50 & 85 & 90 \\
\hline 1 year & $83.9(21.7)$ & $64.0(32.2)$ & 0.05 & 91 & 70 \\
\hline \multicolumn{6}{|l|}{ ODI } \\
\hline Preop & $45.2(19.9)$ & $48.9(14.9)$ & & & \\
\hline 1 month & $24.9(19.8)$ & $43.4(20.5)$ & 0.02 & 74 & 45 \\
\hline 3 months & $18.8(17.4)$ & $38.7(18.0)$ & 0.01 & 84 & 55 \\
\hline 6 months & $17.6(18.1)$ & $29.2(16.4)$ & 0.21 & 81 & 90 \\
\hline 1 year & $13.8(16.1)$ & $25.3(23.8)$ & 0.23 & 88 & 70 \\
\hline
\end{tabular}

Pts $=$ patients.

* For difference in improvement of score.

$\dagger$ Values in this column are mean outcome score (standard deviation). 
that long-term follow-up for several years is essential to understand the economic impact of surgical procedures. ${ }^{24}$ Future economic studies may be required to determine the significant societal costs for lumbar discectomy within the first 3 months as well as over several years following surgery.

The data presented here suggest that patient-reported outcomes (ODI and SF-36) at 3 months after lumbar discectomy are predictive of 1-year outcome for patients who do not require a reoperation. This has implications for how surgeons, patients, payers, and other stakeholders assess quality for lumbar discectomy. These data do not apply to other conditions such as lumbar spinal fusion, which may require several years of follow-up.

\section{Limitations}

This analysis is limited by the lack of a control nonoperative cohort. Without a comparison group, the gain in outcome following surgery may be an overestimate due to effects that would also be present in a nonoperative group, such as the lapse of time, medications, etc. However, we expect that our results would be maintained if we compared the gain in outcome to the gain in outcome in a nonoperative cohort and adjusted accordingly. In addition, our sample size is small and could be influenced by selection bias. It is possible that only favorable patients were selected for inclusion in the study, and in that case the results would be skewed toward demonstrating greater efficacy of lumbar discectomy. Similarly, the number of patients who underwent a reoperation was very small. Larger registries would be necessary to correlate patient-reported outcome data in patients who develop reherniation following the index procedure. In addition, future registry projects might evaluate comparative strategies for managing patients who develop reherniation (nonoperative treatment, revision discectomy, fusion).

\section{Conclusions}

The NeuroPoint-SD registry demonstrated the clinical effectiveness of lumbar discectomy at 1 year. The results of this analysis show that 3-month outcomes may be accurately extrapolated to predict 1-year outcomes for patients who do not require reoperation. Patients with less improvement at 3 months following lumbar discectomy may require additional evaluation. This study sets a foundation for providing guidelines for the duration of collection of patient-reported outcomes following lumbar discectomy. Significant cost savings would be realized by most centers participating in registries by restricting the collection of patient-reported outcome assessment to 3 months for evaluating lumbar discectomy outcome.

\section{Acknowledgment}

The work was coordinated by the NeuroPoint Alliance.

\section{References}

1. Asher AL, McCormick PC, Selden NR, Ghogawala Z, McGirt MJ: The National Neurosurgery Quality and Outcomes Database and NeuroPoint Alliance: rationale, development, and implementation. Neurosurg Focus 34(1):E2, 2013
2. Atlas SJ, Keller RB, Chang Y, Deyo RA, Singer DE: Surgical and nonsurgical management of sciatica secondary to a lumbar disc herniation: five-year outcomes from the Maine Lumbar Spine Study. Spine (Phila Pa 1976) 26:1179-1187, 2001

3. Brazier J, Roberts J, Deverill M: The estimation of a preference-based measure of health from the SF-36. J Health Econ 21:271-292, 2002

4. Brazier J, Usherwood T, Harper R, Thomas K: Deriving a preference-based single index from the UK SF-36 Health Survey. J Clin Epidemiol 51:1115-1128, 1998

5. Brazier JE, Roberts J: The estimation of a preference-based measure of health from the SF-12. Med Care 42:851-859, 2004

6. Deyo RA, Loeser JD, Bigos SJ: Herniated lumbar intervertebral disk. Ann Intern Med 112:598-603, 1990

7. Fairbank JC, Couper J, Davies JB, O'Brien JP: The Oswestry low back pain disability questionnaire. Physiotherapy 66:271-273, 1980

8. Findlay GF, Hall BI, Musa BS, Oliveira MD, Fear SC: A 10year follow-up of the outcome of lumbar microdiscectomy. Spine (Phila Pa 1976) 23:1168-1171, 1998

9. Ghogawala Z, Shaffrey CI, Asher AL, Heary RF, Logvinenko T, Malhotra NR, et al: The efficacy of lumbar discectomy and single-level fusion for spondylolisthesis: results from the NeuroPoint-SD registry: clinical article. J Neurosurg Spine 19:555-563, 2013

10. Gold MR, Franks P, McCoy KI, Fryback DG: Toward consistency in cost-utility analyses: using national measures to create condition-specific values. Med Care 36:778-792, 1998

11. Hägg O, Fritzell P, Nordwall A: The clinical importance of changes in outcome scores after treatment for chronic low back pain. Eur Spine J 12:12-20, 2003

12. Hays RD, Sherbourne CD, Mazel RM: The RAND 36-Item Health Survey 1.0. Health Econ 2:217-227, 1993

13. Jenkins PJ, Clement ND, Hamilton DF, Gaston P, Patton JT, Howie CR: Predicting the cost-effectiveness of total hip and knee replacement: a health economic analysis. Bone Joint J 95-B:115-121, 2013

14. Kepler CK, Wilkinson SM, Radcliff KE, Vaccaro AR, Anderson DG, Hilibrand AS, et al: Cost-utility analysis in spine care: a systematic review. Spine J 12:676-690, 2012

15. Lurie JD, Tosteson TD, Tosteson AN, Zhao W, Morgan TS, Abdu WA, et al: Surgical versus nonoperative treatment for lumbar disc herniation: eight-year results for the spine patient outcomes research trial. Spine (Phila Pa 1976) 39:3-16, 2014

16. Mannion AF, Junge A, Grob D, Dvorak J, Fairbank JC: Development of a German version of the Oswestry Disability Index. Part 2: sensitivity to change after spinal surgery. Eur Spine J 15:66-73, 2006

17. Martin BI, Mirza SK, Comstock BA, Gray DT, Kreuter W, Deyo RA: Are lumbar spine reoperation rates falling with greater use of fusion surgery and new surgical technology? Spine (Phila Pa 1976) 32:2119-2126, 2007

18. McCabe C, Brazier J, Gilks P, Tsuchiya A, Roberts J, O'Hagan A, et al: Using rank data to estimate health state utility models. J Health Econ 25:418-431, 2006

19. Mummaneni PV, Whitmore RG, Curran JN, Ziewacz JE, Wadhwa R, Shaffrey CI, et al: Cost-effectiveness of lumbar discectomy and single-level fusion for spondylolisthesis: experience with the NeuroPoint-SD registry. Neurosurg Focus 36(6):E3, 2014

20. Pappas CT, Harrington T, Sonntag VK: Outcome analysis in 654 surgically treated lumbar disc herniations. Neurosurgery 30:862-866, 1992

21. Patrick DL, Deyo RA, Atlas SJ, Singer DE, Chapin A, Keller RB: Assessing health-related quality of life in patients with sciatica. Spine (Phila Pa 1976) 20:1899-1909, 1995 
22. Peul WC, van den Hout WB, Brand R, Thomeer RT, Koes $\mathrm{BW}$ : Prolonged conservative care versus early surgery in patients with sciatica caused by lumbar disc herniation: two year results of a randomised controlled trial. BMJ 336:13551358,2008

23. Russell LB, Gold MR, Siegel JE, Daniels N, Weinstein MC: The role of cost-effectiveness analysis in health and medicine. JAMA 276:1172-1177, 1996

24. Soegaard R, Bünger CE, Christiansen T, Høy K, Eiskjaer SP, Christensen FB: Circumferential fusion is dominant over posterolateral fusion in a long-term perspective: cost-utility evaluation of a randomized controlled trial in severe, chronic low back pain. Spine (Phila Pa 1976) 32:2405-2414, 2007

25. Spengler DM: Lumbar discectomy. Results with limited disc excision and selective foraminotomy. Spine (Phila Pa 1976) 7:604-607, 1982

26. Taylor VM, Deyo RA, Cherkin DC, Kreuter W: Low back pain hospitalization. Recent United States trends and regional variations. Spine (Phila Pa 1976) 19:1207-1213, 1994

27. Weinstein JN, Lurie JD, Tosteson TD, Skinner JS, Hanscom B, Tosteson AN, et al: Surgical vs nonoperative treatment for lumbar disk herniation: the Spine Patient Outcomes Research Trial (SPORT) observational cohort. JAMA 296:2451-2459, 2006

28. Weinstein JN, Tosteson TD, Lurie JD, Tosteson AN, Hanscom B, Skinner JS, et al: Surgical vs nonoperative treatment for lumbar disk herniation: the Spine Patient Outcomes Research Trial (SPORT): a randomized trial. JAMA 296:24412450, 2006

\section{Author Contributions}

Conception and design: Ghogawala, Mummaneni, Shaffrey, Heary, Asher, Malhotra, Steinmetz, Resnick. Acquisition of data: Ghogawala, Curran, Mummaneni, Shaffrey, Heary, Kaiser, Asher, Malhotra, Cheng, Hurlbert, Smith, Magge, Resnick. Analysis and interpretation of data: Ghogawala, Whitmore, Curran, Mummaneni, Shaffrey, Heary, Kaiser, Resnick. Drafting the article: Ghogawala, Whitmore, Curran, Ali. Critically revising the article: Ghogawala, Mummaneni, Heary, Kaiser, Resnick. Reviewed submitted version of manuscript: Ghogawala, Whitmore, Curran, Mummaneni, Shaffrey, Heary, Kaiser, Asher, Malhotra, Cheng, Hurlbert, Smith. Statistical analysis: Curran, Magge, Steinmetz, Resnick. Administrative/technical/material support: Curran. Study supervision: Ghogawala, Shaffrey, Resnick.

\section{Correspondence}

Zoher Ghogawala, Lahey Hospital and Medical Center, Department of Neurosurgery, 41 Mall Rd., Burlington, MA 01805. email: Zoher.ghogawala@lahey.org. 